\title{
A COMPETENNCIA DE RELACIONAMENTO CONTRIBUINDO PARA O DESENVOLVIMENTO DE CAPITAL SOCIAL DA EMPRESA DE BASE TECNOLÓGICA ${ }^{1}$ \\ THE COMPETENCE OF RELATIONSHIP CONTRIBUTING TO THE DEVELOPMENT OF THE SHARE CAPITAL OF TECHNOLOGY-BASED COMPANY
}

\author{
Fernando Gomes de Paiva Júnior ${ }^{2}$ \\ Nelson da Cruz Monteiro Fernandes ${ }^{3}$ \\ Larissa Fernanda de Lima Almeida ${ }^{4}$
}

\begin{abstract}
RESUMO: Com a emergência das organizações em rede e dos negócios globalizados, o estabelecimento de relacionamentos de cooperação proporciona a diminuição de custos e o incremento de vantagens competitivas. No entanto, estas parcerias falham pela indevida atenção ao componente relacional no âmbito dos negócios. A formação de alianças pressupõe que o conhecimento, a confiança e as redes de relacionamentos proporcionam condições para o alcance de oportunidades e adicionam riquezas que garantem a sustentabilidade das organizações. $\mathrm{O}$ objetivo do estudo reside em observar como a competência de relacionamento atua na agregação desses elementos. Para isto, realizamos uma análise qualitativa de elementos relevantes para promover e sustentar relacionamentos de cooperação. Os resultados demonstram que a sensibilidade interpessoal se destaca como dimensão primordial na qualidade do relacionamento, além de evidenciarem a emergência da capacidade de negociação entre parceiros e promoção de consenso entre os interagentes como elemento constitutivos da capacidade de negociação mantenedora de relações saudáveis. A sustentabilidade do empreendedor nas redes se dá pelo desenvolvimento alianças, e neste cenário, a competência de relacionamento é um elemento chave para o sucesso das parcerias.
\end{abstract}

PALAVRAS CHAVE: Competências empreendedoras, competências de relacionamento, cooperação, empreendedorismo, confiança, capital social.

ABSTRACT: At the new context of the emergency of the network organizations and the global businesses, the establishment of cooperation relationships provides costs reduction and the increment of competitive advantages. However, these partnerships fail because of the low attention to the relational component in business-oriented interpersonal interactions. The formation of alliances indicates that the knowledge, confidence and social network provides conditions for reach opportunities and add wealth that guarantee the sustainability of organizations. The study aims to observe how the relationship competence acts in the aggregation of those elements. We carry through a qualitative analysis of important elements to initiate and keep a cooperation relationship. The results demonstrate that interpersonal sensitivity emerges as primordial dimension in the quality of the relationship, also shows up the emergency of the negotiation ability between partners and promotion of consensus among the actors as the element constituent of the negotiation capacity for maintenance of healthful relations. The entrepreneur's sustainability in the network is supported by the development of alliances, and in this scene the relationship ability is a key element for the success of partnerships.

KEY WORDS: Relationship competences; Entrepreneurship; Cooperation; Trust; Social capital.

\footnotetext{
${ }^{1}$ Artigo Recebido em 19.05.2009. Revisado por pares em 16.04.2010. Recomendado em 19.05.2010 por Leomar dos Santos Editor. Publicado em 08.09.2010.

Organização Responsável pelo periódico: Universidade regional de Blumenau - FURB - www.furb.br/rn
}

\footnotetext{
${ }^{2}$ Universidade Federal de Pernambuco - UFPE - rnando.paivajr@ufpe.br

${ }^{3}$ Universidade Federal de Pernambuco - UFPE - cruzfernandes5@yahoo.com.br

${ }^{4}$ Universidade Federal de Pernambuco - UFPE - larissal.almeida@gmail.com
} 


\section{INTRODUÇÃO}

O processo da globalização pressupõe um crescimento econômico baseado nos livres mercados e nos ganhos de produtividade. Esse fato tem contribuído para intensificar a competição entre indivíduos, empresas, regiões e nações. A busca por novos recursos - conhecimento, informação, competências, capacidade de aprendizado, de inovação e de cooperação - e pela redução de custos leva as empresas a se aglutinarem em redes produtivas globais que constroem um novo formato de produção e relações de trabalho, ao atuarem em contextos de progressiva diferenciação de cenários geográficos e culturais, na medida em que intencionam a acumulação e a gestão de capital (DUPAS, 1999; CASTELLS, 1999).

Esse contexto potencializa o surgimento das redes, que, por sua, vez facilitam o fluxo de recursos, constituindo uma configuração organizacional propulsora de informação e conhecimento. A forma de acumulação e de difusão do capital social acontece através de redes que podem ser constituídas nas esferas dos indivíduos, das organizações e da sociedade. A noção de sistema se forma quando os atores interagem como partes interdependentes, que ajudam a capturar recursos presentes nessa estrutura (ANAND; GLICK; MANZ, 2002; GULATIE; GARGIULO, 1999; YAMADA, 2002). O complexo de instituições, costumes e relações de confiança locais conducentes à cooperação assume um papel crítico para o empreendedorismo, assim como às interações sociais constituem os principais veículos ou canais por meio dos quais o aprendizado e a inovação têm lugar (ALBAGLI; MACIEL 2002).

Os relacionamentos de cooperação atendem ao sistema como estratégia competitiva na busca de sustentabilidade e competitividade, em que os parceiros estabelecem laços com a intenção de diminuir os custos ou agregar valor e competências que tragam benefício mútuo. Além disso, as articulações de rede facilitam o processo de reconhecimento de oportunidades de mercado e o acesso a informação e conhecimento que subsidiam na criação de empresas e na redução dos riscos (CHABAUD; NGIJOL, 2005). No entanto, essas parcerias tendem a falhar quando não há o entendimento de que mais do que uma relação de negócios trata-se de uma interação entre pessoas. Os processos de cooperação também são diversos, conforme o ambiente cultural e institucional em que ocorrem e não podem ser codificados para "receitas" passíveis de reprodução em qualquer outra localidade ou região.

As parcerias se efetivam de acordo com alguns elementos abstratos, dispostos em extratos como confiança, comprometimento e comunicação. Essas variáveis estão contidas na competência de relacionamento dos empreendedores e são relevantes na construção, fortalecimento e manutenção dos relacionamentos. As relações sociais concretas, mais do que dispositivos institucionais ou a existência de uma moral generalizada, são atributos fundamentais para a construção da confiança na vida econômica. A imersão no tecido social (GRANOVETTER, 1985) possibilita a geração de confiança desencorajando comportamentos oportunistas.

Visando delimitar o escopo que define o âmbito das redes, cabe caracterizá-las do ponto de vista do relacionamento social no campo da administração e compreender seu papel como mecanismo indutor da ação empreendedora voltada para a captação de negócios. Um estudo desenvolvido por Singh, Hills e Lumpkin (1999) sugere que os contatos estabelecidos nas redes sociais são cruciais para o reconhecimento de oportunidades pelos empreendedores. Fato já reconhecido por Koller (1988) e respaldado pelos trabalhos de Hills et al. (1997), que registram que cerca de 50\% dos empreendedores lançam idéias para os seus negócios mediante os contatos com pessoas que integram suas redes sociais.

A relacionalidade se manifesta quando o empreendedor, no movimento para a concretização do negócio, busca no outro as competências que lhe faltam; e continua no esforço de comunicação com os parceiros nos diversos níveis, no sentido de entender o outro para facilitar a interação e alcançar um resultado profícuo. Esse movimento está ancorado em uma razão relacional, cujo princípio reside no fato de que relações 
potencializadas para ganhos coletivos estão acima de ações atomizadas ${ }^{5}$ voltadas para ganhos individuais (LIN, 1999; PAIVA Jr., 2004).

As redes que compõem parte importante dos clusters na dinamização da cadeia integrada, formada por atividade de agregação de valor, podem, por meio de esforços de cooperação, proporcionar vantagens na sua forma de organização, tais como a diluição do risco, o compartilhamento de recursos para se evitar a duplicação onerosa de esforço independente, a maior geração de flexibilidade e um melhor acesso a know-how e à informação (CLEGG e HARDY, 2007).

As relações interfirmas, no entanto, não são pautadas apenas por esferas de cooperação num prisma simétrico, a considerar a existência de conflitos de interesses entre os integrantes de uma rede interorganizacional. Segundo ARAÚJO (2000), estas relações são permeadas por integração e dependência assimétrica entre as partes, considerando que a colaboração implica freqüentes interações e, conseqüentemente, aumenta o potencial para conflitos e divergências. Em geral, uma das partes tem tendência a exercer um ascendente sobre a outra, seja por razões de dependência ou de conhecimento assimétrico.

Por outro lado, Souza et al (1997) argumentam que nesse novo tipo de arranjo organizacional as assimetrias entre os participantes tendem a desaparecer e a relação não fica apenas marcada pelo poder de imposição de uma parte sobre a outra, sob a justificativa de que deverá ser preservada a "resistência" da rede no longo prazo.

Deste modo, a essência da discussão consiste justamente em questionar até que ponto o cenário de redes, tal como se apresenta, constitui um espaço benigno para a geração de uma atmosfera adequada aos seus objetivos de satisfação empresarial.

Em sendo a competência relacional elemento da prática empreendedora articulada na rede do empreendedor, necessária para a mobilização do capital social imerso nessa rede e fonte valiosa de obtenção de recursos, este estudo visa descrever como a competência de relacionamento auxilia no fortalecimento dos laços de cooperação do dirigente da empresa de base tecnológica.

\section{COMPETÊNCIA RELACIONAL E CAPITAL SOCIAL: A ARTICULAÇÃO SIMBIÓTICA}

As mudanças ocorridas no ambiente exigem do indivíduo um comportamento reflexivo de aprendizagem na ação. Essa transição de paradigmas fundamentada na qualificação técnica e, portanto, preso às características do cargo, para outro onde a flexibilização das organizações exige a mobilização da subjetividade de modo que o sujeito tenha autonomia decisória.

Existem três aspectos que caracterizam e transformam esse novo paradigma, conforme declara Zarifian (2001), quais sejam: a tomada de iniciativa e responsabilidade pela aprendizagem; a inteligência prática das situações ancoradas nos conhecimentos adquiridos; a faculdade mobilizadora de redes de atores em torno situações comuns, co-responsabilidade e compartilhamento de resultados, que corrobora com as características de autonomia, senso de responsabilidade e relacionalidade associadas ao empreendedor.

As competências podem ser definidas como a habilidade de unir e combinar os elementos necessários ao empreendimento de determinada ação baseada em um resultado pretendido, dimensionadas em individuais, grupais ou organizacionais (RUAS; ANTONELLO; BOFF, 2005). Mello, Leão e Paiva Júnior. (2006) definem competências como características que englobam diferentes traços de personalidade, habilidades e conhecimentos. No estudo com empreendedores de êxito socialmente reconhecido no eixo Rio-São Paulo, sob inspiração dos estudos de Man e Lau (2000), os autores constataram a existência de sete competências empreendedoras distintas, mas que se complementam numa espécie de interface conceitual e prática. Quais sejam:

\footnotetext{
${ }^{5}$ Ações desenvolvidas de forma isolada, sem considerar os aspectos da coletividade.
} 
A competência de oportunidade que corresponde à capacidade de o empreendedor observar 0 meio, identificar e atuar sobre potenciais chances de negócio; as competências conceituais se referem à percepção de situações sob ângulos diferentes, e à habilidade de encontrar alternativas para essas questões; as competências administrativas dizem respeito à adequada alocação de recursos; as estratégicas estão relacionadas à escolha e implementação de estratégias empresariais; as competências de comprometimento indicam a habilidade de manter o foco, o direcionamento e a dedicação do dirigente ao negócio, mesmo em situações adversas; a competência de equilíbrio trabalho/vida pessoal é a capacidade de atender a ambas as demandas, e as competências de relacionamento, a capacidade de criação e fortalecimento de redes de relacionamento (Mello, Leão e Paiva Jr, 2006).

A preocupação com o relacionamento em rede (networking) é fundamental para o desenvolvimento profissional e se expande gradativamente para o cotidiano das pessoas como prática inexorável de sobrevivência num saber-fazer relacional (netliving) (MINARELLI, 2001). Essa competência agrega valor ao desenvolvimento pessoal e empresarial por meio da expansão do empreendimento, assim como na esfera da identificação e validação de oportunidades de negócio.

Daremos ênfase aqui à competência de relacionamento, que se revela como a dimensão fundamental para a formação da cooperação dos interagentes da rede. Essa competência, por meio da troca de informações e da potencialização dos processos de aprendizagem, aperfeiçoa o nível de inovação nas empresas e potencializa o acesso aos recursos necessários à sua produção (MELLO; LEÃO; PAIVAJUNIOR, 2006).

O acesso aos recursos oriundos da sua rede social ocorre por meio do ativo capital social acumulado nas relações sociais. Para Bourdieu (1980), o capital social é o conjunto de recursos atuais ou potenciais que estão ligados por posse de uma rede durável de relações mais ou menos institucionalizadas de reconhecimento mútuo. É a própria relação que permite acesso a recursos adquiridos pelas associações assim como é a responsável pela qualidade e a quantidade desses recursos.

Coleman (1994) assevera que o capital social compreende um aspecto da estrutura social e facilita certas ações dos indivíduos dentro da estrutura. Como outras formas de capital, o capital social é produtivo, tornando possível a realização de certos fins que na sua ausência seriam impossíveis. Já Putnam(2000) refere-se ao capital social relacionado a aspectos da organização como normas, confiança, cadeia de relações sociais que facilitam a cooperação para benefícios mútuos.

Na perspectiva do indivíduo as questões são da ordem de como ele acessa e utiliza os recursos imersos na rede para obter ou manter ganhos. Apesar de, no momento em que o indivíduo se beneficia de seu investimento e um grupo se beneficia, os ganhos individuais retornam para o coletivo (LIN, 1999b).

Segundo essa perspectiva o capital social se dá no contexto das redes sociais e pode ser definido como "os recursos imersos na rede social acessado e utilizado pelos atores para ações” (LIN, 2001, p. 25). Os recursos são bens de valor consensualmente determinados por uma sociedade segundo seus valores e cuja possessão assegura os interesses individuais de preservação, na maioria das sociedades correspondem a riqueza, reputação e poder (LIN, 1999a).

\section{1 - Competência de Relacionamento}

As competências relacionais são fontes geradoras de identificação de oportunidades e geração de negócios por meio da captação e utilização dos recursos inerentes à rede pessoal do empreendedor. Essa performance interativa é realizada pela confluência de esforços entre os atores organizacionais, na forma de acoplagem de competências, dirigida ao alcance da visão empreendedora (FILION, 1999). 
O ato de construir e conservar os relacionamentos com os parceiros é representativo e está previsto nos estudos de Moger (2000), que denomina os empreendedores como ativadores de rede, compreendendo-os como pessoas de habilidades de relacionamento junto a grupos de referência. Esses sujeitos estabelecem relações estratégicas com clientes, governos, concorrentes, entidades de apoio e demais instituições que lhe gerem significados compartilháveis, buscando intercambiar informações sobre fatos e dinamizar o processo inovador.

O investimento efetuado por atores articulados em seus relacionamentos se molda pela atração de recursos que possibilite o seu desenvolvimento. Isso constitui uma chancela social por meio da qual os indivíduos ou grupos acessam e absorvem recursos dispersos no ambiente, à medida que reforçam sua identidade cultural e se tornam reconhecidos no espaço social. Tal agenciamento valida à importância da rede de relacionamentos na condição de ambiente para obtenção de capital econômico-financeiro e intelectual, inclusive por meio da aprendizagem, a considerar que nesses arranjos estruturais as informações trocadas ajudam no desenvolvimento do processo de inovação (LIN, 2001; MELLO; LEÃO; PAIVA JUNIOR, 2006).

Para que as parcerias sejam efetivas, é imperativo que os potenciais parceiros compartilhem de ferramentas e conhecimentos e acreditem que o esforço coletivo trará resultados satisfatórios. A confiança representa um componente primordial dessa parceria e sua construção envolve um entendimento das relações negociais na esfera da eqüidade. Isso pressupõe a conscientização de que a geração de negócios é um processo bilateral no qual os interagentes devem compreender o desdobramento da ação na alçada coletiva, onde as partes trabalham movidas pela condição de fidelidade, de modo a evitar a fragilização ou esfacelamento da interação.

O construto confiança é relevante para o estrato de posicionamento de negócios e ampliação da base mercadológica empresarial, uma vez que ela suscita credibilidade, o que na esfera da prática de negócios gera propagação do resultado empresarial ancorado por pilares sustentáveis de fidelidade (PAIVA JUNIOR; MELLO; GONÇALVES, 2005).

O comprometimento com as redes sociais remete ao senso de sustentabilidade dos negócios, o qual se baseia na compreensão da textura de laços pessoais do empreendedor como ativos intangíveis e diferenciados que permitem o desenvolvimento dos negócios vigentes, além da identificação e a validação de novas oportunidades negociais.

\section{2 - Formação de alianças como dinâmica de cooperação}

A emergência das organizações centradas no conhecimento e a economia baseada em redes elucidam as formas dos relacionamentos interorganizacionais como interações que influenciam as estratégias das firmas. As alianças são fontes significativas de recursos, de aprendizagem e, conseqüentemente, de geração de vantagem competitiva. Elas constituem o capital social atrelado às atividades orgânicas do empreendedor e propiciam benefícios econômicos e sociais no modo em que:

- Facilitam o fluxo de informações, o fortalecimento de laços sociais em posições estratégicas e podem prover o indivíduo e potenciais parceiros de insights sobre oportunidades, disponibilidades e interesses que de outra forma não estariam disponíveis.

- Influenciam os agentes que possam ter influência nas decisões estratégicas. Neste caso, alguns nódulos de prestígio atados aos laços não periféricos, dependendo de sua localização e posicionamento, exercerem maior poder político.

- Oferecem credenciais sociais. Os recursos dos laços e seu conhecimento das relações podem servir ao indivíduo como credencial social, na medida em que vão dando a ele acesso a recursos só disponíveis por meio da sua rede social. Nessa perspectiva, Granovetter (1985) assevera que os danos à reputação é o maior custo de um comportamento oportunista. 
A emergência do tema do capital social impõe a necessidade de se considerarem e as relações sociais como fundamentais para se compreender e intervir sobre a dinâmica econômica. Como destacaram Johnson e Lundvall (2000): “capital social não é, obviamente, um mero estoque de algo que pode ser simplesmente acumulado. É, na verdade, um conjunto de instituições em sua maioria informais (hábitos e normas sociais), que afetam os âmbitos de confiança, interação e aprendizado em um sistema social".

Os resultados positivos desses relacionamentos surgem quando do desenvolvimento de competências a partir da integração de recursos, e da troca de conhecimentos. Axelrod (1985) declara que a cooperação é desenvolvida a partir de interesses individuais alcançáveis a partir de uma ação coletiva, para tanto é necessário que haja uma relação duradoura, o que pressupõe conhecimento e conseqüentemente menor desconfiança, também a existência de interesses comuns e a disponibilidade de um resultado onde haja ganhos mútuos.

A capacidade colaborativa surge quando há indivíduos predispostos a estabelecer relações de apoio e reciprocidade, baseadas na confiança de tal modo que gerem recursos que seriam inviáveis se não fosse à associação coletiva (RODRIGUES, 2002).

A cooperação pode conter um paradoxo: na busca de seus objetivos é necessário a supressão dos propósitos de ganho individual da empresa em nome de uma aliança, no entanto um comportamento contrário resultaria um ganho coletivo insatisfatório. Para que esse empreendimento seja exitoso, as relações devem ser de equidade e os comportamentos oportunistas rechaçados. Uma vez que há reciprocidade, a punição pela oposição restabelece o equilíbrio das relações. Isto pode ser observado em situações em que a busca da otimização de seus interesses individuais levam a um resultado sub-ótimo para todas as partes.

Conforme assevera Putnam (1993) a interação promove um desenvolvimento de normas, valores e confiança que são o eixo para a produção e manutenção do bem estar da sociedade. Dessa forma, ele consolida alianças estratégicas sob a égide da sinergia que impulsiona a organização na busca de oportunidades. Por isso, essa junção articulada de atores com espírito de trabalho convergente pode ser o fator chave no desenvolvimento de empresas em mercados emergentes, principalmente aquelas centradas em conhecimento e transferência de tecnologia (YAMADA, 2002; OLIVEIRA, 2004).

A formação de alianças está relacionada ainda ao reconhecimento de oportunidade que é um processo que repousa geralmente nas interações que o empreendedor estabelece com o seu entorno (HILLS, 1995; HILLS, LUMPKIM; SINGH, 1997). Ao estar em contato com diversas redes ele é confrontado com visões de mundo diferentes conseguindo enxergar as lacunas e podendo servir de ponte entre elas, sendo esta uma condição dinâmica e adaptável favorável à inovação (CHABAUD; NGIJOL, 2005).

\section{3 - Contribuição da competência de relacionamento para a formação de cooperação}

O processo empreendedor é tão complexo e desafiador que indivíduos com capacidades diversas precisam se unir. O capital social atua aí como um eixo que mantém as pessoas unidas por meio de expectativas e crenças comuns. A junção de pessoas que confiam umas nas outras e se identificam entre si constitui uma sociedade inseparável (JOHANISSON, 1998).

O estabelecimento de relacionamentos leva ao entendimento de que a cooperação permite certa estabilidade proveitosa para o crescimento e multiplicação das competências a partir do somatório das qualidades dos parceiros. A rede pode ser fonte de legitimação, além de oferecer suporte, insight, credibilidade, contatos e facilitar o acesso à capitalização.

As relações sociais representam o construto das redes, definidas por Prenkert e Hallen (2006), como a interconexão das relações de negócios, nessa estrutura as interações entre as conexões de negócios interferem uma na outra, fazendo com que diferentes relações conversem entre si. Essa organização não tem centro nem limites e pode ocorrer 
em todas as direções, embora as interações impliquem em um fluxo de trocas mútuas e bilaterais, na lógica da rede, essas trocas se tornam multilaterais e multidirecionais.

A posição das redes organizacionais se revela como espaço vulnerável a ações oportunísticas de empecilho ao crescimento das empresas de menor porte e ao mesmo tempo um universo benigno para o desenvolvimento da cooperação entre elas, principalmente no que concerne à sinergia na inovação tecnológica e geração de oportunidades de negócios (PAIVA JUNIOR, 2001).

A capacidade do empreendedor de formar redes sociais dá sustentabilidade ao empreendimento, nesse ponto é importante estabelecer relações de igualdade, onde habilidades efetivas de comunicação serão fundamentais para o estabelecimento de relações duradouras e para o surgimento de oportunidades de negócios. O comportamento de uma comunicação consiste na qualidade total, na informação que compartilham e participação de uma comunicação (MOHR; SPECKMAN, 1994). O empreendedor recorre a essas relações como fontes de conhecimento, informações ou capacidades dos parceiros que possam contribuir com a sua atividade. A rede social consiste numa estrutura flexível, dinâmica, auto-organizada, na qual cada indivíduo tem um papel e as relações estabelecidas entre os indivíduos compõem a temática da rede (TOMAÉL; ALCARÁ; DI CHIARA, 2005).

A competência relacional utilizada para construir ligação de confiança gera credibilidade no empreendedor sendo também extensiva ao empreendimento e a sua rede social. Esta última, por sua vez, sustenta a expansão do empreendimento a partir da fidelidade ao gerar relações duradouras que fortalecem a marca corporativa e proporcionar vantagem competitiva por meio da diferenciação com capacidade de geração de novos negócios. A imitação da confiança é dispendiosa para o concorrente por se constituir uma prática socialmente complexa, sendo difícil de ser compreendida e implantada como artefato estratégico em outras empresas (HITT; IRELAND; HOSKISSON, 2002).

O termo rede designa acordos de cooperação econômica entre países, alianças estratégicas entre organizações, interação de grupos, conjunto de contatos desenvolvidos por uma pessoa ao longo da vida e fator de vantagem competitiva para a obtenção de um emprego (LOPES E MORAES, 2000). As redes sociais, de acordo com Elias (1994), formam uma ponte entre indivíduos e sociedade, ação e estrutura. $\mathrm{O}$ autor propõe a noção de redes de funções como uma perspectiva que procura ultrapassar a dualidade indivíduo versus sociedade, realçando a interdependência entre estes elementos. De acordo com Granovetter (1992) as redes são formadas por laços que podem ser fortes, fracos ou ausentes. O que caracteriza a intensidade do laço é a combinação entre tempo, intensidade emocional, confiança mútua e serviços recíprocos (GRANOVETTER, 1992).

\section{PROCEDIMENTOS METODOLÓGICOS}

Este estudo foi realizado junto a duas empresas de base tecnológica do pólo de tecnologia da informação da Região Metropolitana do Recife (RMR). Vale salientar que o pólo digital pernambucano tem se mostrado um dos mais prósperos do setor de base tecnológica nacional e um dos principais clusters de TI (Tecnologia da Informação) da América Latina. Essa peculiaridade enseja um ambiente de negócios altamente competitivo e dinâmico. Neste contexto, buscamos dirigentes de empresas de êxito socialmente reconhecido na atividade empresarial, o que pressupõe a emergência de indícios de habilidades empreendedoras na busca por vantagem competitiva e sustentabilidade do empreendimento.

Foram entrevistados dois dirigentes de empresas de pequeno e médio porte que atuam nesse cenário. A empresa Alfa é uma das empresas de desenvolvimentos em informática mais conhecidas do mercado. Surgiu a 12 anos, em uma pequena sala com apenas uma mesa e duas cadeiras emprestadas. Os seus primeiros projetos foram 
produzidos em março de 1991, mas ela só foi realmente firmada em outubro daquele ano. Depois disso, ela não parou mais de crescer somando produtos e projetos bem sucedidos. A empresa está sediada em Recife, mas ela está presente em 22 estados brasileiros. São mais de 220 entidades que confiam seus sistemas a essa empresa. No mercado desde janeiro de 2000, a empresa Beta se centra na criação de produtos inovadores no mercado de entretenimento eletrônico, tendo se estabelecido como referência no desenvolvimento de jogos multiplayer on-line, simulações (game-based learning) e advergames. Dentre seus principais clientes estão a Goodyear, Coca-Cola, Brasil Telecom, MTV, o SEBRAE. Com sede no coração do Porto Digital, a empresa participa ativamente do desenvolvimento do mercado nacional de jogos e é membro da Associação Brasileira das desenvolvedoras de Jogos Eletrônicos.

Esse ambiente parece exigir empreendedores com perfil reflexivo e capacidade de aprendizagem na ação. Assim sendo, a consciência crítica de busca da compreensão sóciohistórica e cultural possibilita a construção de conhecimentos especializados que permitem aos empresários a absorção de recursos necessários ao desenvolvimento da competência relacional na perspectiva da interação com os diversos stakeholders.

A busca de compreensão de um fenômeno sob o olhar indutivista é uma das características da abordagem de pesquisa qualitativa (CRESWELL 1998; MINAYO, 2000). Essa pesquisa parte de um paradigma compreensivo de construção social da realidade. Alinhados a essa perspectiva, pressupomos que a realidade é concebida por significados atribuídos pelo sujeito empreendedor, na qual apreciamos suas várias construções e significações (BERGER; LUCKMANN, 1973).

Para o tratamento analítico dos dados, escolhemos a análise de conteúdo temática (BAUER; GASKELL, 2002; MINAYO, 2000). Essa estratégia permitiu a compreensão do processo de desenvolvimento de competências relacionais por meio dos relatos baseados na experiência vivida do dirigente. Vale ressaltar que utilizamos essa técnica em sua acepção não tradicional, a qual pressupõe a emergência do significado em detrimento da freqüência de aparição de determinado item ao longo de uma narrativa.

Essa variação da análise de conteúdo é tratada por Bardin (2004), como uma alternativa para uma abordagem de pesquisa qualitativa. Segundo o autor

pode se dizer que a característica da análise qualitativa é o fato da inferência sempre que é realizada - ser fundada na presença do índice (tema, palavra, personagem, etc!), e não sobre a freqüência de sua aparição, em cada comunicação individual (BARDIN, 2004. p. 109).

Depois da entrevista e da transcrição dos dados, fizemos uso de leituras flutuantes com o intuito de nos familiarizarmos com os achados e ultrapassarmos a sensação de caos inicial característico dessa etapa (MINAYO, 2000). Posteriormente, realizamos a constituição do corpus no que se refere à organização do material considerando os elementos de exaustividade (levantados no protocolo de pesquisa, no nosso caso, relativos aos indícios de desenvolvimento de competências de criação e desenvolvimento de relacionamentos); representatividade (representação do universo pretendido nessa pesquisa, o caso único relacionado à emergência de elementos de construção da competência relacional e sua contribuição no fortalecimento do capital social); homogeneidade (o estabelecimento de critérios precisos de escolha em termos de temas, técnicas e interlocutores); e a pertinência dos documentos analisados em relação ao objetivo da pesquisa. Esses tópicos iniciais são compreendidos no plano de uma préanálise, na qual foram determinados os recortes e as unidades de significado sob a forma de síntese. A forma de categorização - fundada na perspectiva teórica de Filion (1999), Mello, Leão e Paiva Jr. (2006) e Meddeb (2003) facilita sua compreensão com o suporte dos conceitos teóricos temáticos que orientaram a análise dos dados. 
A fase seguinte envolveu a exploração do material sob a forma dos fragmentos de texto escolhidos de acordo com os preceitos teóricos e achados relativos. Na seqüência, realizamos a agregação dos dados. Nesse momento, delimitamos as categorias teóricas baseadas nos achados teóricos de Phan et al (2005), e empíricas compreendidas sob o olhar dos temas relacionados às competências empreendedoras de criação e desenvolvimento de relacionamentos.

Temos ciência da limitação da técnica de analise de conteúdo, na medida em que as informações estão sujeitas apenas à interpretação do entrevistado, bem como pela compreensão do pesquisador (TRIVIÑOS, 1987; CRESWELL, 1998). Desse modo, a fase de tratamento dos resultados foi perpassada por idas e vindas interpretativas com apoio dialógico do auditor da investigação (MERRIAM, 1998). Esse processo recursivo permitiu consubstanciar a análise dos dados por meio dessas atividades de validação. Desse modo, utilizamos elementos de auditoria de investigação com o intuito de preservar a consistência do processo analítico da emergência de vieses interpretativos.

A reflexividade foi uma constante forma de atenuar elementos limitantes que restringissem a qualidade das entrevistas e análises de campo. Assim, lembramos a orientação de Creswell, (2002) de que a reflexividade é um critério de confiabilidade e diz respeito ao antes e ao depois do acontecimento, gerando transformação no pesquisador, uma vez que este vai se tornando uma pessoa diferente por considerar as inconsistências do estudo ao longo do processo permanente de realização. Desse modo, percebemos que o ator, historicamente fazedor da ação empreendedora, contribui para significar o nosso universo pesquisado, exigindo uma constante reflexão e reestruturação do nosso processo de questionamento.

Em suma, é imperativo, num estudo qualitativo, desenvolver uma noção de contexto de quem atua num intercâmbio direto com seu ambiente natural e se estabeleça por mediação das características particulares da sociedade a que pertence. Assim, quando se pretende estudar a evolução da sociedade, é necessário partir do exame empírico dos processos concretos da vida social que constituem condição da existência humana em interação (GIDDENS, 2000).

\section{ANÁLISE DOS RESULTADOS}

A reflexão se concentra em torno do processo de manutenção dos relacionamentos para o fortalecimento das alianças que podem prover a qualidade das relações. A busca de solução conjunta de problemas é expressa por um comportamento comunicativo pautado pelo intercambio de informações estratégicas, condição que se contabiliza com os achados e reflexão de Julien (2010). Portanto, as decisões acertadas na rede são conseqüências desse esforço com implicações na utilidade, oportunidade e credibilidade no âmago das articulações de rede que geram a expansão do capital social. Sob esse prisma, os resultados serão apresentados visando substanciar as respostas para atender aos objetivos do estudo: a visão geral dos resultados das competências será feita a partir de uma análise das diferentes dimensões.

Como se pode observar na tabela 1, a dimensão assertividade foi a que apresentou a maior freqüência de citações, uma vez que representa aproximadamente a metade das enunciações. Isso pode ser esclarecido pelo fato de a seleção dos parceiros representarem um ponto crítico de confiabilidade e reputação no estabelecimento das suas relações. Nesse âmbito, elementos como credibilidade, reciprocidade e competências complementares são significativos para o alcance do sucesso das alianças (DAS; TENG, 1998).

Tabela 1 - Competência para iniciar relacionamento 


\begin{tabular}{|c|c|c|c|}
\hline \multicolumn{4}{|c|}{ Fonte: Pesquisa direta (2005). } \\
\hline Código & Variáveis & Freq. & $\%$ \\
\hline 101 & Assertividade & 18 & 45 \\
\hline 102 & Dominação & 10 & 25 \\
\hline 103 & Competência instrumental & 12 & 30 \\
\hline \multicolumn{2}{|r|}{ Total } & 40 & 100 \\
\hline
\end{tabular}

A competência instrumental está relacionada à acoplagem de competências, vindo a constituir um elemento relevante na dinâmica da ação empreendedora, além de ser característica intrínseca das relações de cooperação, conforme ilustra o relato de um entrevistado:

P:Você acha que sozinho não funcionaria tão bem?

R:Não. Quem tem nas veias o sangue do empreendedor cria muito e corre muito. Tem que ter alguém atrás arrumando, dando forma às idéias. Você acha que J. seria capaz de criar sozinho? Jamais. Mas é porque ele explode de idéias e há pessoas que vão atrás, construindo as idéias.

A dimensão dominação foi a menos freqüente das três, fato que pode elucidar o fato de a natureza da ação coletiva estar contemplando o princípio da equidade. Por outro lado, Moniz e Kóvacs (2001) reconhecem que as relações tendem a ser assimétricas embora, por definição, a parceria manifeste uma configuração de negócio na qual as partes trabalham de forma colaborativa e compartilham as responsabilidades gerenciais (solução conjunta dos problemas). Sob esse prisma, se um dos sócios mostrar uma tendência à dominação, o parceiro poderá perceber isso de forma negativa, o que tende a se repercutir na fragilização dos laços da rede, conforme discutido por Paiva Jr. \& Barbosa (2001).

Quanto mais os sócios compartilham informações significativas e quanto mais eficazes e oportunas estes sejam conteúdos, mais efetivas se tornarão as decisões tomadas, o papel do empreendedor no âmbito da parceria estará sendo contemplado e a aliança terá maiores chances de êxito.

\begin{tabular}{l|l|c|c|}
\hline \multicolumn{4}{|c|}{ Tabela 2 - Competência mantenedora de relacionamento } \\
\hline Fonte: Pesquisa direta (2005). & Freq. & $\mathbf{\%}$ \\
\hline Código & Variáveis & 8 & 10,2 \\
\hline 111 & Intimidade & 18 & 23,07 \\
\hline 112 & Confiança & 24 & 30,79 \\
\hline 113 & Sensibilidade interpessoal & 12 & 15,3 \\
114 & Altruísmo & 16 & 20,5 \\
\hline & Tomada de perspectiva & $\mathbf{7 8}$ & $\mathbf{1 0 0}$
\end{tabular}

No que diz respeito à competência mantenedora de relacionamento expressa na tabela 2, a dimensão sensibilidade interpessoal foi a mais presente ao longo dos diálogos e está relacionada à tomada de perspectiva, uma vez que ambas habilitam os parceiros a enxergar a partir da realidade do outro, de modo a facilitar as interações, como nos elucida o trecho a seguir: "É procurar entender o universo das pessoas, eu acho que é uma coisa muito razoável a se fazer ...”. Essa conexão articulada de atores pode ser uma tarefa primordial no processo de criação de empresas em mercados emergentes, especialmente aquelas centradas em conhecimento e transferência de tecnologia (YAMADA, 2002; OLIVEIRA, 2004). 
A confiança também apareceu como dimensão de destaque no estabelecimento das parcerias, nesse sentido a troca de informações verdadeiras e a percepção de que o interagente da rede não será enganado está diretamente relacionada à consolidação da conivência entre as partes. Isso reforça a leitura de Phan et al. (2005), quando declara que em um contexto de parceria de negócio sem propensão à confiança entre os parceiros emergem os motivos para suspeitas entre eles, decorrentes do medo de trapaça ou embuste, atos que desencadeiam comportamento de desconfiança e provocam a erosão do relacionamento. O trecho seguinte ilustra bem isso: "Eu jogo na confiança, tem o risco, o caminho é muito mais longo, agora, é mais perene!”. Paiva, Jr.; Mello e Gonçalves (2005) reforçam que a confiança ocasiona credibilidade que suscita a propagação de resultado sustentáveis de fidelidade, ampliando a base de ancoragem empresarial no mercado.

\begin{tabular}{l|l|c|c|}
\hline \multicolumn{3}{|c|}{ Tabela 3 - Qualidade de Relacionamento } \\
\hline Fonte: Pesquisa direta (2005). & Freq. & $\%$ \\
\hline Código & Variáveis & 13 & 19,7 \\
121 & Confiabilidade & 13 & 19,7 \\
\hline 1211 & Credibilidade & & \\
1212 & Benevolência & 4 & 6,0 \\
\hline 122 & Satisfação & & \\
1221 & Satisfação com os outros dirigentes (interpessoal) & 22 & 33,3 \\
\hline 123 & Comprometimento & & \\
1231 & Comprometimento pessoal dos (dirigentes) para com o relacionamento & 14 & 21,3 \\
\hline 124 & Solução conjunta de problemas & 66 & 100 \\
\hline 1241 & Capacidade de resolução de conflitos & & \\
\hline & Total &
\end{tabular}

A qualidade de relacionamento é definida como uma construção de ordem maior, composto de confiança interpessoal (BOLES et al., 2000), satisfação com os outros parceiros, comprometimento com as relações e solução conjunta de problemas (MOHR; SPECKMAN, 1994).

Conforme o disposto na tabela 3, para a manutenção da qualidade do relacionamento, o construto de maior realce é o comprometimento que contempla um terço das citações referentes à variável de qualidade de relacionamento. Corroborando com o argumento de Paiva Júnior. (2005) de que o senso de dever transforma-se em credibilidade. Além disso, a confiança que os membros de uma rede depositam no empreendedor é útil para angariar o seu comprometimento social e econômico.

Entendemos que esse comprometimento não diz respeito apenas às relações de negócio, mas se refletem também na manutenção de um convívio próximo entre os parceiros. Assim, a capacidade de resolução de conflitos constitui o elemento constante das alianças, devido à natural interdependência das partes, e isso explica a importância desse item quando sua efetividade está atrelada ao comprometimento para com o outro, argumento reforçado pelas dimensões como credibilidade e benevolência.

Lembro-me de uma dessas crises no setor, na qual o superintendente da empresa veio conversar comigo. Pediu de maneira muito gentil, mas muito preocupado, para reduzir os custos.[...] Ele propôs uma redução de 18 para 14 salários mínimos [...] minha contraproposta foi indexar a consultoria pelo preço do frango: se o frango baixasse, ele diminuiria o valor da consultoria, se aumentasse, meu pagamento aumentaria automaticamente. Houve um momento no qual eu estava ganhando tanto dinheiro que fiquei com vergonha. Não cabia cobrar tanto por tão pouco na relação que estava estabelecida. Estava ganhando 32 salários mínimos. Ia apenas uma vez por semana na empresa e mesmo assim ele manteve o pagamento, alegando que na hora do sufoco eu havia contribuído e que 
era a vez dele contribuir. Ele foi extremamente ético e a relação tornou-se bastante duradoura.

Tabela 4-Comportamento comunicativo

\begin{tabular}{l|l|c|c}
\hline \multicolumn{3}{c}{ Tabela 4 - Comportamento comunicativo } \\
\hline Fonte: Pesquisa direta (2005). & Freq. & $\mathbf{\%}$ \\
\hline Código & Variáveis & & \\
131 & Qualidade da comunicação & 14 & 21,8 \\
\hline 1311 & Oportunidade, precisão, utilidade e credibilidade da informação. & 8 & 12,5 \\
\hline 1312 & Negociar com parceiros de negócios & 21 & 32,8 \\
\hline 1313 & Promoção de consenso entre parceiros & & \\
\hline 132 & Troca de informações & 14 & 21,9 \\
1321 & Provisão proativa de informações críticas, confidenciais e úteis ao & & \\
\hline 1331 & outro dirigente. & & 11 \\
& Participação & & \\
\hline & A extensão na qual os dirigentes se empenham conjuntamente no \\
& planejamento e definição de metas & $\mathbf{6 4}$ & $\mathbf{1 0 0}$
\end{tabular}

A tabela 4 reforça o caráter relacional e comunicacional da ação empreendedora. Ireland, Hitt e Vaidyanath (2002) afirmam que a excessiva especialização e o hermetismo de seus componentes representam um dos elementos ameaçadores da cooperação, constatação que coaduna com os achados de Fritsch e Kauffeld-Monz (2010) quando declaram que se deve manter em mente que a imersão excessiva em laços fortes pode levar a hermetismo ou morte entrópica da rede, gerando também efeitos negativos sobre o desempenho da inovação. Esses autores acrescentam que as empresas podem alcançar o equilíbrio ótimo entre os laços fortes e inserção no ambiente.

Assim, para que a rede continue a lograr êxito e se manter integrada é fundamental a orquestração das competências onde o elemento de maior expressão foi a promoção de consenso entre parceiros, que de forma semelhante à dimensão negociação com parceiros foi identificada como relevante para a promoção de consenso e a solução adequada de conflitos. Inclusive, esse elemento não constava nos estudos de Phan et al., (2005), tendo sido identificado ao longo desta pesquisa. Ambas variáveis são relevantes, pois como evidencia Ireland et al., (2002) o comportamento competitivo é um grande desafio ao estabelecimento das alianças e a habilidade do dirigente em convencer os parceiros dos benefícios das ações coletivas em detrimento de ações percebidas como vantajosas individualmente serão determinantes para o êxito da relação e ganho mútuo.

Eu vou lhe propor um negócio é a primeira frase... Eu tenho que apresentar o negócio mostrando onde é que você vai ganhar. Se não for assim, como é que eu vou despertar seu interesse? Agora, cabe a você dizer: “como é que eu vou ganhar dinheiro?” Aí, eu vou explicar: é assim, assim, assim. E faz: “e você entra aonde?” Eu entro aqui e tal, e vou ganhar aqui. Se eu não explicar a você como é que eu vou ganhar, você também não vai acreditar. Você me propor um negócio onde só quem ganha sou não existe. Para você ganhar dinheiro, é assim, assim, e eu vou ganhar aqui. Está vendo quanto eu vou ganhar? Pronto. Você vai ganhar aqui. E aí o cara diz: “poxa, é mesmo. Vamos lá”. Se não for assim, não vai.

Considerando o fenômeno da competência de relacionamento sob o marco do capital social destaque-se o processo de comunicação em meio a uma atmosfera de assertividade, sensibilidade ao outro e manutenção de atitudes de confiança, benevolência e credibilidade no coração dos nódulos da rede.

De toda a forma, o intercambio de informação que integra o empreendedor ao seu grupo de referência torna patente às tensões provocadas pelas assimetrias subjacentes ao processo de tomada de decisão articulada nesse meio. Logo, por intermédio do conhecimento, o empreendedor vai penetrando nos vários espaços disponíveis na rede e, de alguma forma, se apropriando deles. Sendo assim, a partir desse objeto de relação do ator 
com sua estrutura vale compreender a complexidade de sua posição junto aos interagentes, refletir sobre os significados e valores que emergem da interação e, enfim, reconhecer as implicações dos relacionamentos que perpassa os vários lugares do poder, as representações, os marcos regulatórios e suas inter-relações com as culturas vigentes nos domínios das redes sociais.

\section{CONCLUSÕES}

Após as considerações levantadas com base nos dados teóricos e empíricos aqui apresentados revisitamos a problemática norteadora como pauta de achados e reflexões em torno da investigação: descrever como a competência de relacionamento auxilia no fortalecimento dos laços de cooperação da empresa de base tecnológica.

O pólo digital de Pernambuco é um espaço de forte articulação, por ser um setor novo, ainda pequeno, mas com empresas atuando na esfera do mercado mundial. Seus participantes vêem na competência de relacionamento a força necessária para lidar com aspectos que envolvem a atividade empreendedora, a exemplo de disputas políticas, concorrência e aproveitamento de oportunidades.

A assertividade emerge como dimensão fundamental para se iniciar um relacionamento de parceria seguida de competência relacional que está remetida à acoplagem de competências e se vincula diretamente à escolha dos melhores parceiros para se trabalhar. A sensibilidade interpessoal aparece como um elemento positivo na manutenção dos relacionamentos, já que numa parceria ver o mundo pela perspectiva do outro pode contribuir para a tomada de decisão mais acertada para ambos. Esse construto tem relação direta com a variável tomada de perspectiva, e juntas às habilidades de percepção as situações pelo olhar do outro supera, em número de citações, o elemento confiança, apontado pela maior parte da literatura como o mais importante no estabelecimento de alianças.

Quanto à percepção do relacionamento como de qualidade, o comprometimento surge como a variável forte e nos remete a pensar que quando o parceiro percebe que o outro está empenhado em manter a laços saudáveis este se esforça para responder a altura, desenvolvendo características de benevolência e credibilidade. Este argumento reforça a capacidade de busca conjunta de soluções de problemas, já que esses interagentes estarão dispostos a ceder por acreditar que o outro está comprometido com a manutenção da cooperação.

No que se refere ao comportamento comunicativo, a qualidade e troca das informações são importantes, assim como a oportunidade, utilidade, e credibilidade que farão com que os parceiros tomem decisões mais acertadas. De forma semelhante o intercâmbio de informações estratégicas propicia às partes a possibilidade de alcançar um desempenho individual superior, e, conseqüentemente, contribui de forma efetiva para a coletividade.

A sustentabilidade do empreendedor nas redes é perpassada pelo desenvolvimento de alianças obtidas por meio de formas de integridade na interação social, que pressupõe a criação de vínculos sociais duradouros. Reforçando o nosso argumento de que a competência de relacionamento é critica para o êxito das parcerias que o empreendedor de base tecnológica estabelece no seu ambiente direto e além-fronteiras. A competência relacional utilizada para construir relações de confiança gera credibilidade que sustenta a expansão do empreendimento a partir da fidelidade, gerando relações duradouras que fortalecem o empreendimento e proporcionam vantagens competitivas por meio da diferenciação com capacidade de geração de novos negócios.

Os relacionamentos de cooperação requerem relações de confiança, acordos sobre os movimentos, sentimento de pertencimento e de destinos ligados, equilíbrio de poderes, troca de informações transparentes e compartilhamento de valores logo, os empreendedores têm que conhecer os parceiros com que dialogam. As disfunções no processo de interdependência existentes nas redes de relacionamento são o reflexo imediato da corrida para o alcance de maior produtividade e competitividade. Esse 
fenômeno impele as relações a caminharem à margem de mecanismos de regulamentação e de uma ética coletiva. Tais exigências de competitividade e resultados têm conduzido as interações a uma aprendizagem relacional assimétrica ao longo da cadeia.

Para que essas parcerias sejam efetivas a escolha de parceiros com credibilidade, valores e objetivos comuns é um aspecto relevante. Os elementos ligados ao entendimento do outro como tomada de perspectiva e sensibilidade interpessoal também merecem destaque. Se os empreendedores ou as pessoas chave de determinada organização não tiverem os atributos da competência de relacionamento, eles devem refletir sobre formas humanizadas de [re] educação e treinaremento para aprender a desenvolver e dinamizar esses traços de comportamento. O desafio essencial neste novo paradigma consiste em combinar diversos graus de negociação, de visibilidade e de possibilidades de aprendizagem compartilhadas que impulsionam a interdependência produtiva entre as os dirigentes das pequenas, médias e grandes empresas.

Os avanços com iniciativas de inovação e compartilhamento de práticas criativas entre os integrantes das redes sociais podem representar uma importante fonte de oportunidade de captação de negócios para as pequenas e médias empresas (PMEs), tendo em vista que cada firma tenderá a explorar as externalidades específicas do sistema por meio de mecanismos de aprendizagem interativa de atividades similares, numa atmosfera de estreita colaboração interfirmas.

Embora tenha sido realizada com empreendedores de êxito socialmente reconhecido e com representatividade no seu meio, uma limitação dessa pesquisa foi o número reduzido de casos: foram entrevistados dois empreendedores de empresas de base tecnológica. Assim, ela apresenta um panorama da realidade de empresas de base tecnológicas da RMR, sugerimos que sejam realizadas investigações em diferentes regiões do país. Além disso, seria interessante que fossem desenvolvidos estudos com outras tradições de pesquisa de modo a permitir uma posterior meta análise do tema em futuras investigações.

*Agradecemos ao CNPq pela realização deste estudo.

\subsection{REFERÊNCIAS}

ANAND, V.; GLICK. W.; MANZ, C. Capital social: explorando a rede de relações da empresa. Revista de Administração de Empresa. v. 42, n. 4, 2002, p. 57-71.

ALBAGLI, S.; MACIEL, M. L. Capital social e empreendedorismo local. In: Proposição de Políticas para a Promoção de sistemas produtivos locais de micro, pequenas e médias empresas. Apoio FINEO, CNPq e SEBRAE. 2002. Disponível em: http://www.ie.ufrj.br/redesist/NTF2/NT SaritaMLucia.PDF. Acesso em: 12 jan. 2007

ARAÚJO, L. As relações interorganizacionais. In RODRIGUES,S. B. e CUNHA, M.P.(orgs.). Estudos organizacionais: novas perspectivas na administração de empresas: uma coletânea luso-brasileira. São Paulo: Iglu, 2000.

AXELROD, R. The evolution of Co-operation. New York: Penguim Books, 1985.

BARDIN, L. Análise de Conteúdo. 3. ed. Lisboa: Edições 70, 2004.

BERGER, P. I; LUKMANN T. A construção social da realidade: tratado de sociologia do conhecimento. Petrópolis: Vozes, 1973. 
BAUER, M. W.; GLASKELL, G. Pesquisa qualitativa com texto imagem e som: um manual prático. Petrópolis: Vozes, 2002.

BOLES, D.; FALKE, J.; SYKESS, R.; DYER, L.; ABERA, S.; CHOI, G. Gender Differences in Consumer Behavior. 2003. Disponível em: www.danboles.com. Acesso em: 12 jan. 2007

CASTELLS, M. A Sociedade em rede. 3. ed. São Paulo: Paz e Terra, 1999.

CHABAUD, D.; NGIJOL J. La contribution de la théorie des réseaux sociaux à la reconnaissance des opportunités de marche. Revue internationale de PME, v. 18, n. 1, 2005.

CLEGG, S. R.; HARDY, C. Introdução: organização e estudos organizacionais. In CLEGG, S. R.; HARDY, C.; NORD, W. R..(orgs. ed. inglesa) e CALDAS, M.; FACHIN, R.; FISCHER, T. (orgs. ed. brasileira). Handbook de estudos organizacionais, v.1. São Paulo: Atlas, 2007.

CRESWELL, J. W. Qualitative inquiry and research design: choosing among five traditions. Londres: Sage Publication, 1998.

Research design: qualitative, quantitative and mixed methods approaches. 2.ed. Londres: Sage Publication, 2002.

DAS, T.; TENG, B. Between trust and control: developing confidence in partner cooperation in alliances. Academy of management review, v. 23, n. 3, jul., 1998, p.491-512.

DUPAS, G. Economia global e exclusão social. São Paulo: Paz e Terra, 1999.

ELIAS, N. A Sociedade dos Indivíduos. Rio de Janeiro: Jorge Zahar Editor, 1994.

FILION, L. J. Empreendedorismo: empreendedores e proprietários - gerentes de pequenos negócios. Revista de Administração da USP, vol. 34, n. 2, 1999.

FRITSCH, M.; KAUFFELD-MONZ, M.. The impact of network structure on knowledge transfer: an application of social network analysis in the context of regional innovation networks. Annals of Regional Science, 44, 2010, p.21-38.

GRANOVETTER, D. Economic action and social structure: the problem of embeddedness'. In Granovetter, M. and Swedburg, R. (eds) The Sociology of Economic Life. Oxford: Westview Press. 1992.

GRANOVETTER, M. Economic Action and Social Structure: the problem of Embeddedness. American Journal of Sociology vol. 91, n. 03, 1985.

GIDDENS, A. The Third Way and its critics. Cambridge: Polity Press, 2000.

GULATI, R.; GARGIULO, M. Where do interorganizational networks come from? American Journal of Sociology, v. 104, n. 5, 1999, p. 1439-1493.

HILLS, G. E. Opportunity recognition by successful entrepreneurs: a pilot study. Frontiers of entrepreneurship research. Wellesley: Mass. Babson College, 1995.

HILLS, G. E., LUMPKIN, T. G.; SINGH, R. P. Opportunity recognition: perceptions and behaviors of entrepreneurs. Frontiers of entrepreneurship research. Wellesley: Mass. Babson College, 1997. 
HITT, M. A.; IRELAND, R. D.; HOSKISSON, R. E. Administração estratégica: competitividade e globalização. São Paulo: Thomsom, 2002.

IRELAND, R.; HITT, M.; VAIDYANATH, D. Alliance Management as a source of competitive advantage. Journal of management, v.28, n.3, p.413-446, 2002.

JOHANNISON, B. Entrepreneurship as a collective phenomenon. RENT XII, Lyon: novembro, 1998, p.l-41.

JOHNSON, B.; LUNDVALL, B. A. Promoting Innovation Systems as a Response to the Globalising Learning Economy. In: CASSIOLATO, J. E.; LASTRES, H. M. M. (orgs.). Seminário Internacional Arranjos Produtivos Locais e Novas Políticas de Desenvolvimento Industrial e Tecnológico. Rio de Janeiro: BNDES e FINEP, 2000. Disponível em: http://www.race.nuca.ie.ufrj.br/gei/ativid/projetos/gil/particip/jcassio.htm. Acesso em: 12 jan. 2007.

JULIEN, P. Empreendedorismo regional: economia do conhecimento. São Paulo: Saraiva, 2010.

KOLLER, R. H. On the source of entrepreneurial ideas. Frontiers of Entrepreneurship Research. Wellesley, MA: Babson College, 1988.

LIN, N. Social Networks and Status Attainment. Annual Review of Sociology 25:467-87. 1999. Press 2001.

N. Social capital, a theory of social structure \& action. Port Chester, Cambridge University

LOPES, H. E. G.: MORAES, L. F. R. Redes e organizações: algumas questões conceituais e Analíticas. ENEO, 1., 2000, Curitiba. Anais do... Curitiba, 2000.

MAN, T. W.Y.; LAU, T. Entrepreneurial competencies of SME owner/manager in the Hong Kong services sector: a qualitative analysis. Journal of Entreprising Culture, v. 8, n. 3, 2000.

MEDDEB, B. L. Organisation du III millénaire: quelles compétences pour le manager. Organisations \& Territoires. v.12, n.1, 2003.

MELLO, S. C. B.; LEÃO. A. L. DE S.; PAIVA JÚNIOR., F. G. Competências Empreendedoras de Dirigentes de Empresas Brasileiras de Médio e Grande Porte que Atuam em Serviços da Nova Economia. Revista de Administração Contemporânea - RAC, v. 10, n. 4, out./dez., 2006.

MERRIAM, S. B. Qualitative research and case study applications in education: revised and expanded from case study research in education. 2. ed. San Francisco-CA: Jossey-Bass Education Series and the Jossey-Bass Higher Education Series, 1998.

MINARELLI, J. A. Networking. São Paulo: Gente, 2001.

MINAYO, M. C. O desafio do conhecimento: pesquisa qualitativa em saúde. 7.ed. São Paulo: Hucitec, 2000. 
MOGER, S. Enhancing the marketing/entrepreneurship interface in SMEs - the contibution of metwork activation. Anais do I EGEPE - Encontro de Estudos sobre Empreendedorismo e Gestão de Pequenas Empresas. Maringá-PR, 2000.

MOHR, J. J.; SPECKMAN, R. Characteristics of partnership success: partnership attributes, communication behavior, and conflict resolution techniques. Strategic Management Journal, v. 15, n. 2, 1994.

MONIZ, A. B.; KÓVACS, I. A. Condições de cooperação interempresas no conceito de empresa virtual: o caso do setor automobilístico em Portugal. In: N. Guimarães \& S. Martin (ed.). Competitividade e desenvolvimento: atores e instituições locais. São Paulo: Editora SENAC, 2001.

OLIVEIRA, R. Capital social e sua importância para as organizações. In. $3^{\circ}$ Workshop Internacional sobre Comunidades Costeiras. Recife, 2004.

PAIVA JÚNIOR., F. G.; BARBOSA, F. Redes organizacionais no sistema de clusters: reflexões sobre sua posição estratégica na busca de oportunidades pelas pequenas e médias empresas. In: XXV Encontro Nacional de Pós-Graduação em Administração, Campinas SP, 2001.

.; BARBOSA, F.V.;GONÇALVES, C.A.; PEREIRA, V. Redes Organizacionais no Sistema de Cluster: reflexões sobre sua posição estratégica na busca de oportunidades pelas pequenas e médias empresas. México-DF, México. Cladea, 2001

O empreendedorismo na ação de empreender: uma análise sob o enfoque da fenomenologia sociológica de Alfred Schultz. 2004. Tese (Doutorado) - Centro de PósGraduação e Pesquisas em Administração. Universidade Federal de Minas Gerais UFMG, Belo Horizonte, 2004.

O Empreendedor e Sua Identidade Cultural: em Busca do Desenvolvimento Local. In: XXIX Encontro Nacional De Pós-Graduação Em Administração. Brasília - DF, 2005.

; MELLO, S. C. B.; GONÇALVES, C. A. Competitividade e inovação influenciando o crescimento empresarial: a perspectiva dos empreendedores de base tecnológica. XXIX Encontro Nacional De Pós-Graduação Em Administração. Brasília - DF, 2005.

PHAN, M.; STYLES, C.; PATTERSON, P. Relational competency's role in Southeast Asia business partnerships. Journal of business research v.58, 2005, p.173-184.

PRENKERT, F.; HALLEN, L. Conceptualising, delineating and analysing business networks. European Journal of Marketing. v. 40, n. 3/4, 2006, p. 384-407.

PUTNAM, R. The prosperous community: social capital and public life. The American Prospect, v.4, n. 13, 1993.

RODRIGUES, M. L. Sociologia das profissões. Oeiras, Portugal: Celta Editora, 2002.

RUAS, R. L.; ANTONELLO, C. S.; BOFF, L. H. Aprendizagem organizacional e competências. Porto Alegre: Bookman, 2005. 
SINGH,R.P.; HILLS, G. E.; LUMPKIN, G. T.. New Venture Ideas and Entrepreneurial Opportunities: Understanding the Process of Opportunity Recognition. Chicago: Institute for entrepreneurial Studies.University of Illinois at Chicago, 1999.

TOMAÉL, M.I.; ALCARÁ, A.R.; DI CHIARA, I.G. Das redes sociais à inovação. Ci. Inf. , Brasília, v.34, n.2, p. 93-104, mai/ago, 2005

TRIVIÑOS, A. N. S. Introdução a pesquisa em ciências sociais: a pesquisa qualitativa em educação. São Paulo: Atlas, 1987.

YAMADA, J. Entrepreneurship as knowledge and social capital creation: theorical analysis of the startup stage of firms. Departament of Economics, Kawaga University, 2002.

ZARIFIAN, P. Objetivo competência: por uma nova lógica. São Paulo: Atlas, 20001. 